\title{
CASE OF BONY UNION
}

or

\section{A FRACTURE}

or

\section{THE NECK OF THE FEMUR}

WITHIN THE CAPSULE,

OCCURRING IN A YOUNG SUBJECT.

BY EDWARD STANLEY, F.R.S.,

LECTURER ON ANATOMY AND PHYSIOLOGY, AND ASSISTANT SURGEON TO ST. BARTHOLOAEW'S HOSPITAL.

READ 27TH MAY, 1833.

A young man in his eighteenth year fell from the top of a loaded cart upon his right hip, the injury of which was attended by the following symptoms. He was wholly unable to move the limb, and suffered severe pain when it was moved by another person. The thigh was bent to a right angle with the pelvis, and could not by any means be extended. Abduction of the thigh was difficult. The limb was everted, at first slightly, afterwards in a greater degree. The soft parts around the hip joint were considerably 
swollen. There was no shortening of the limb, but rather the appearance of a lengthening of it in the erect posture, probably from the obliquity in the position of the pelvis. No crepitus could be felt in any movement of the limb.

The foregoing symptoms were not considered to indicate conclusively the existence either of dislocation or fracture. The age of the patient was unfavourable to the occurrence of a fracture of the neck of the thigh bone, the general opinion therefore of the several surgeons to whose judgement the case was submitted, favouring the belief of a dislocation into the foramen ovale, forcible extension of the limb was made by means of the pulleys, and the thigh then moved in several directions, by which the head of the bone might be replaced in its socket.

About two months after the accident, the patient was received into St. Bartholomew's Hospital. His health was now found to be much deranged. His pulse was frequent and hard. He complained of pain in the head, also in the injured hip, and down the opposite thigh. This illness was considered to be the effect of cold, but it did not yield to the treatment which was adopted. He remained nearly in the same state for about a month, and during this period, on account of the derangement of the health, no examination was made of the injured hip. At length, eruptions appeared generally 
over his body, which were considered to be small pox, and in two days afterwards, he died.

In the examination of the body, no other morbid appearances were discovered besides those of the injured hip joint. The capsule of the joint was entire, but a little thickened. The ligamentum teres was uninjured. A line of fracture extended obliquely through the neck of the femur, and entirely within the capsule. The neck of the bone was shortened, and its head, in consequence, approximated to the trochanter major. The fractured surfaces were in the closest apposition, and finally united nearly in their whole extent by bone. There was an irregular deposition of bone upon the neck of the femur, beneath its synovial and periosteal covering along the line of the fracture.

The foregoing case is remarkable from the occurrence of a fracture of the neck of the femur within the capsule at an early age, and it is I believe the only example of it on record. In the memoirs of the Academy of Surgery *, Sabatier has related the case of a boy aged 15, in whom, after a fall upon the hip, lameness ensued, and sometime afterwards, a shortening of the limb to the extent of three inches, with a projection of the trochanter major, and an inclination of the whole limb inwards. The patient recovered sufficiently well to be able to walk, but with a consi-

* Tom. x. 12mo. edit. 
derable restraint in the movements of the thigh. Here it may be presumed a fracture had occurred, but it is certain that the seat of it could not have been within the capsule of the hip joint from the great extent of the shortening of the limb.

It will be remarked that in the instance now recorded, notwithstanding the free and repeated examinations of the limb, and the forcible extension of it by the pulleys, in short with every circumstance except the age of the patient, unfavourable for a bony union of the fracture, this had been nearly completed. If this case had occurred at an advanced period of life, we may be certain that there would have been but a very imperfect union of the fracture, and it shews satisfactorily, that in the ordinary cases of fracture of the neck of the femur within the capsule, the age of the patient and consequent deficiency of vascular action, especially in the separated head of the bone, is the most influential of the causes to which the failure of a bony union has been in general ascribed. 